\title{
ENTUSIASMO, DE ALEXEI BUENO, E A POÉTICA DO ENFRENTAMENTO DO MISTÉRIO
}

\section{ENTUSIASMO, BY ALEXEI BUENO, AND THE POETIC OF MYSTERY'S FACEMENT}

\author{
Suene Honorato de JESUS ${ }^{8}$
}

RESUMO: O poema Entusiasmo, de Alexei Bueno (1998), realiza dois movimentos: constatação da indiferença geral para com a vida e proposição de um novo olhar sobre ela. Entre eles, a negação do sujeito é uma constante. Analisaremos essa constante partindo da ideia de sujeito como todo e qualquer indivíduo e também como poeta, especificamente. Para isso, examinaremos alguns conceitos básicos do Romantismo, momento em que a subjetividade se coloca em primeiro plano. Assim, poderemos compreender como a negação do sujeito tem lugar no poema, formulada pelo procedimento da ironia. O poeta consegue reconstituir a noção de sujeito para promover a identificação com o outro e com o mundo à sua volta e propõe uma alternativa, mesmo que precária, para o enfrentamento do mistério resultante da separação entre sujeito e objeto observada na modernidade.

PALAVRAS-CHAVE: Poesia brasileira contemporânea; Alexei Bueno; Negação do sujeito.

ABSTRACT: The poem Entusiasmo, by Alexei Bueno (1998), performs two operations: finding the general indifference to life and proposing a new look about it. Among them, the denial of the subject is a constant. We will analyze this constant according the idea of subject as any individual and also as a poet, specifically. For so, we will examine some basic concepts of Romanticism, when subjectivity stands in the foreground. Thus, we can comprehend how the denial of

\footnotetext{
${ }^{8}$ Doutoranda do Programa de Pós-Graduação em Teoria e Hitória Literária (Bolsista CNPq) - Instituto de Estudos da Linguagem - Universidade Estadual de Campinas (UNICAMP) - CEP 13083-859 Campinas - SP - Brasil - E-mail: suenehonorato@gmail.com
} 
subject takes place in the poem, formulated by the process of irony. The poet can reconstitute the notion of subject to promote identification with the others and the world around him and proposes an alternative, albeit precarious, to face the mystery of the resulting separation between subject and object found in modernity.

KEYWORDS: Brazilian contemporary poetry; Alexei Bueno; Denial of subject.

O poema Entusiasmo, de Alexei Bueno, termina com os seguintes versos: "Esta é a embriaguez. Tomai e bebei todos vós. / Fulgura uma grande luz. Todos dançamos / Perante a porta" (BUENO, 1998, p. 106). O final conclamatório concentra a motivação do poema: acenar, por meio da embriaguez, para a possibilidade de comunhão entre todos os homens. A citação bíblica e a luz fulgurante reforçam a necessidade de reconstituição do sentido da vida pela filiação intemporal ao sagrado. Os verbos no presente ("fulgura" e, correlatamente, “dançamos") indicam não o instante, mas a ausência do tempo, como tentativa de manutenção desse estado de abertura para o mundo, que o poeta chama de "entusiasmo". De acordo com Pinheiro (2008, p. 23; aspas do autor),

[...] entusiasmo é o termo grego utilizado para designar todo estado paradoxal de perda de si em proveito de uma potência - e nesse sentido também de uma alteridade - divina. O ‘sujeito’ tomado pelo entusiasmo - ou pelo transporte (metáfora) divino - não está mais 'em si', mas 'fora de si' e 'em deus' (én-theos).

O sujeito tomado de entusiasmo concretiza o exercício de alteridade em direção ao sentido sagrado da existência. Porém, é preciso notar que, embora a citação se refira ao ritual da Santa Ceia em que Cristo convida ao banquete de seu corpo e sangue, não é ele aqui quem o faz, e sim o poeta. A porta em frente à qual se dança está fechada e a celebração ocorre sem que ela se abra. Pois esta é a "[...] porta do Mistério, / A sem porteiro, a de onde não respondem, / A que talvez não exista, a por onde entramos talvez [...]" (BUENO, 1998, p. 102). 
Se a proposta de comunhão finaliza o poema de maneira tão premente, é porque antes o seu negativo foi indiciado: ausência de comunhão, de abertura para o mundo, de deus no mundo dos homens, de sentido para a existência. Escrito em 1997 durante pouco mais de uma semana, em suas pouco mais de vinte páginas o poema se apresenta ao leitor como um grito de indignação ante a indiferença geral que o poeta parece observar no mundo. Corroboram essa impressão o fluxo contínuo da linguagem em versos livres, as pródigas enumerações, o endereçamento de perguntas e o tom muitas vezes interjeitivo. O movimento feito pelo poema conduz o leitor da constatação da indiferença manifestada pelas vidas anônimas e sem brilho - contrapostas aos momentos de glória na História da humanidade - à busca de alternativa para o restabelecimento de sentido para a vida. Esses dois momentos se intercalam até os últimos versos, que fixam uma possível experiência com o sentido de totalidade. Não se deixa de assinalar que essa alternativa seja precária, pois é permeada pela embriaguez da linguagem, que, além de não constituir estado permanente, realiza-se por meio de um instrumento não mais investido da força fundante que o mito bíblico da criação lhe atribuiu.

Porém, no movimento que faz, o poema apresenta uma constante: a negação da existência do sujeito, formulada de diversas maneiras desde a primeira estrofe:

Roçam-se em mim, incontadas, as vidas todas - e as vidas de cada vida Como um turbilhão de pássaros que o vento assopra no mar queixoso.

Mas em mim não existe, o eu foi deixado há muito tempo,

Longe, como um par de sapatos domésticos de viajante, Abandonados, por uso excessivo, numa cidade qualquer

Não sou, sou o oco, sou o ar onde os pássaros se movem

Pelas brincadeiras do vento. Todos vêm a mim, todos fogem de mim,

E de $e u$, que restou? Estou impuro, estou imundo

Das crostas do existir a vida, como um que se erguesse de dentro de um [pântano,

A lama a soterrar-lhe as formas. Sou o oco da estátua de bronze Antes que o metal escorra

$[\ldots]$

(BUENO, 1998, p. 83). 
O trecho evidencia o desgaste da noção de sujeito. As metáforas apontam, ao mesmo tempo, o turbilhão de vidas que avassalam a percepção do eu e sua afirmação excessiva, o que a esvazia de sentido e requer seu abandono. A negação de si começa pela simples formulação do "não sou" e vai se intensificando com os acréscimos que seguem: afirmação de ser o vazio, ser perpetrado por outros sentidos, ser rejeitado, perder a forma devido à assimilação de todas as vidas e, por fim, ser o vazio da forma antes que esta se fixe. Como consequência do desgaste da noção de sujeito, o poema assinala a separação entre sujeito e objeto, sintomática da indiferença percebida pelo poeta:

Tudo que houve se desmentiu, tudo criou, perene

Um corpo monstruoso que vive e que não é, o corpo do que não é o

[ser.

Andamos dentro dele, vazios de toda a cognição e toda a verdade.

As ruas todas do mundo, os atalhos, os becos, as estradas

São as veias e as artérias do seu corpo inapreensível

Onde escorremos, no nosso peculiar ritmo de insetos

(Se nos veem de muito alto), como um anêmico sangue que se desfaz

[julgando viver

$[\ldots]$

(BUENO, 1998, p. 85).

O “corpo monstruoso que vive e que não é" figurativiza o mundo objetivo, descrito como um Monstro cuja existência não reconhecemos, porque o sujeito está esvaziado de percepção. Embora vazio, o sujeito é o sangue que preenche as artérias desse Monstro, mas não consegue acessá-lo. Por isso o sangue que corre não tem consistência, não confere vida. Separados sujeito e objeto, ambos são impedidos de existir.

Embora a separação entre sujeito e objeto seja iminente na metafísica clássica, a percepção aqui indicada denuncia uma atitude passível de ser situada no que se convencionou chamar modernidade, momento em que ela teria se fortalecido tendo-se em vista a consolidação e consequente desgaste da noção de sujeito. Partindo-se do pressuposto de que o Romantismo inaugura algumas das linhas de força da 
modernidade, procuraremos analisar a negação do sujeito no poema em duas perspectivas: entendendo o sujeito como todo indivíduo e, especificamente, como poeta.

Uma das maneiras de se compreender a modernidade, ainda tão indefinida, é olhá-la a partir de seu extremo, ou seja, as sociedades arcaicas, o que dá a medida da drasticidade das transformações sofridas dentro de uma escala temporal. É possível, numa explanação um tanto quanto vaga, vislumbrar o homem antigo como aquele que dominava todos os processos envolvidos em sua sobrevivência, quer no âmbito material, quer no espiritual. Para Lukács (2000, p. 31), o mundo grego em que floresceu a epopeia homérica era um mundo "perfeito e acabado" em sua dimensão restrita:

Pois totalidade, como prius formador de todo fenômeno individual, significa que algo fechado pode ser perfeito; perfeito porque nele tudo ocorre, nada é excluído e nada remete a algo exterior mais elevado; perfeito porque nele tudo amadurece até a própria perfeição e, alcançando-se, submete-se ao vínculo.

O sentido está presente no mundo grego porque nele ser e objeto, embora separados, se reconciliam na ação, pois ao agir sobre o mundo à sua volta o homem traça em torno de si mesmo um círculo fechado onde "[...] o fogo que arde na alma é da mesma essência que as estrelas." (LUKÁCS, 2000, p. 25). Se a maneira de o homem se reconhecer no mundo passa pela sua relação com o objeto, pode-se dizer que, tanto quanto na modernidade, o homem antigo se espelhava no mundo objetivo, transformado segundo sua atuação; porém, a natureza dessa atuação e, consequentemente, o produto e a imagem dela resultantes é que se tornam fundamentalmente distintos na modernidade. A partir do Iluminismo, o homem passa a se espelhar no mundo objetivo de uma maneira específica, não mais pautada em mitologias, mas no conhecimento racional como forma de apreensão, domínio da realidade. Em A dialética do esclarecimento, Adorno e Horkheimer (1985) procuram mostrar como a razão esclarecida não logrou aproximar sujeito e objeto na tentativa de tornar o mundo menos obscuro. Ao contrário, ela expropriou o domínio irracional instaurando outro que se torna tanto mais obscuro na medida em que oferece um mundo objetivo destituído de sentido, reduzido a fórmulas. Assim, alarga-se o abismo entre sujeito e objeto, pois a promessa de 
esclarecimento se converte em mais um modo de não se acessar o mundo objetivo. Daí dizer-se que o sujeito moderno é alienado, isto é, separado do mundo.

Voltando a Entusiasmo, podemos notar que a separação entre sujeito e objeto, entre o eu e sua percepção do mundo, geram o esvaziamento do sujeito: "Pasto dos homens, cansei-me de ti! / Role o mundo para onde rolar, [...] / Sua trajetória não me interessa. Sairei em breve. Tudo é sempre breve. / Breve é a eternidade, e o egoísmo metafísico me paramenta como a um rei [...]" (BUENO, 1998, p. 86). Diante disso, não há o que dizer sobre a vida: "Que falaremos da vida?” (BUENO, 1998, p. 83, 85 e 103), repete o poeta. A afirmação do eu se afigura mais como máscara discursiva, convenção linguística, do que como consciência de si. Nela está contida a indiferença a si e ao mundo, como demonstra o seguinte trecho, onde a repetição da palavra "eu" destaca-se de maneira nauseante:

$\mathrm{Eu}$,

Fragmento bípede do acaso,

Eu, majestaticamente indiferente à minha própria história e a seu [desfecho,

Eu, fantasia de um Carnaval de todos os dias que o absurdo arrasta [entre as portadas

$[\ldots]$

(BUENO, 1998, p. 104).

Importa notar que a noção de sujeito ganha maior relevância a partir do Romantismo, em contraste com as ideias iluministas - que os românticos enxergaram como "conceitos limitantes acerca do homem e do mundo" (NUNES, 1978, p. 56) -, inclusive no ramo das ciências objetivas. As primeiras manifestações de uma filosofia romântica na Alemanha surgem a partir das proposições do idealismo fichteano em Fundamento de toda teoria da ciência (FICHTE apud BORNHEIM, 1993, p. 85), que se baseiam na concepção do "Eu puro", princípio metafísico, para explicar toda a realidade, pois só ele pode dar origem ao pensamento puro que é capaz de criar todas as coisas, “[...] não só as coisas extramentais, representadas, mas também a substancialidade do eu, a razão individual." (BORNHEIM, 1993, p. 86). Porém, não se deve reduzir o Romantismo à subjetividade, contraposta à objetividade presente no 
Neoclassicismo. Como assinala Vizzioli (1993, p. 140), “[...] o Romantismo não expulsou a razão; apenas a integrou num contexto mais amplo, onde o principal elemento conformador seria o sentimento." Tanto para o Romantismo quanto para o Neoclassicismo, os dois elementos são determinantes da relação entre homem e mundo; a diferença reside na ênfase que recai sobre cada um deles - diferença que se justifica segundo a culminância de tensões que já vinham se desenvolvendo no mundo ocidental no sentido de reabilitar a intuição intelectual para as artes do pensamento, o que se pode verificar, por exemplo, nas obras de Rousseau, Descartes e Kant (BORNHEIM, 1993).

Da súmula cartesiana que funda o eu pensante como princípio da existência, os poetas românticos derivam o "sinto, logo sou" (BORNHEIM, 1993, p. 95), decorrente da ênfase no aspecto subjetivo. Em Entusiasmo, o "penso, logo existo" recebe mais uma correção:

Penso, eu que não existo, agora, no ator transformista Vanderli

Cantando a Balada dos loucos na boate turbulenta.

Infinita graça que se foi, trapos e panos lantejoulados se rasgando

No número portentoso,

$\mathrm{E}$ as pequeninas contas rolando, refletidas nas garrafas,

Cheias de luzes, como átomos ou astros no tabuleiro torto do Acaso

$[\ldots]$

(BUENO, 1998, p. 85-86; grifo nosso).

Da correção dos românticos à empreendida pelo poema, enfatiza-se o desgaste da noção de sujeito, tanto quando formulada racionalmente como quando formulada sob o primado da subjetividade. Assim, não é apenas o sujeito poético que, embora pensante, desaparece na negação, mas também sua identificação com o outro. Se ele não existe, inexiste também o objeto de que fala: o número do ator transformista Vanderli. Porém, a qualidade pensante desse sujeito tão inexistente quanto seu objeto permite que ele reestruture o quadro poético em que esse número se dá. Apesar de não ser mais do que um anônimo, seu número é portentoso: o milagre que opera é fazer que o reflexo das contas nas garrafas simbolize os astros girando no tabuleiro do Acaso, o que não é senão traduzir com outras palavras o sentimento de totalidade experimentado por meio da ação que Lukács atribui ao homem antigo, referido anteriormente. 
A ausência desses momentos de "infinita graça" resulta na noção de esvaziamento do sujeito, que se amplia do "eu" para o "nós":

E tudo é venda, véu, fumaça, cerração, neblina

Como em nossa vida os fios de bicho-da-seda do que fomos,

Opaco casulo que, nos envolvendo, nos refaz partidos

E de onde nada de alado nunca sairá

$[\ldots]$

(BUENO, 1998, p. 88).

Composto pela soma de todo o passado, o "opaco casulo" de onde nada afeito ao voo resultará se relaciona à impossibilidade de glória para todos nós e, portanto, de manutenção do sentido de beleza, vislumbrada nos fios do bicho-da-seda que contrastam com a opacidade do casulo. A beleza está naquilo que foi. Porém, essa constatação não deve resultar em indiferença. O poeta pergunta: "Quais são, relembrando tudo, os momentos plausíveis da humanidade? / O que pesam as horas de glória na balança viciada de todas as vidas?” (BUENO, 1998, p. 87). A História é feita de grandes acontecimentos, ao passo que nossas vidas são prosaicas e destituídas de beleza. Mas não só porque somos pessoas comuns, e sim porque qualquer tipo de heroísmo foi impossibilitado na medida em que temos de arcar com a soma de todos os acontecimentos do nosso passado histórico. Assim, o peso da balança acusa positivamente para os anônimos. Mas aqui a medida é quantidade (a soma das vidas anônimas e seus feitos é maior que a soma dos momentos de glória), e não qualidade da experiência vivida. Por isso, o brilho da glória ainda turva nossos olhos. O poeta assume o desejo falido de ascensão:

Estou de uma sinceridade absoluta, estou despido

Como nunca estive, depois de um demorado aprendizado.

Parca vida cheia de reflexos de ouro. Alexei, quantas catedrais,

Kremlins e arcádias poderiam estar bordadas entre as letras desse

[nome

Onde não há mais eu? A brincadeira acabou-se. Foi-se o prolixo

[conto.

Meu coração é as pedrinhas da rua, por onde todos os sapatos 
[retornam

$[\ldots]$

(BUENO, 1998, p. 87).

A nudez da sinceridade impede que a autonomeação se concretize enquanto afirmação da noção de sujeito, pois "Alexei" é apenas um nome esvaziado de existência. A impossibilidade de que este nome remeta a grandes conquistas, das quais só percebe reflexos, faz que o poeta se identifique com o que há de mais ordinário: pedras da rua pisadas por todos os passantes. Esta mesma sinceridade leva o poeta a perguntar: "Quando a beleza se foi, que restou além de ti, verdade? / Sem os aurigas coroados sob o sol, ficou-nos a nudez dos nossos olhos" (BUENO, 1998, p. 91). Admite-se aqui que os reflexos projetados pelo passado sobre o presente ofuscam nossa percepção para a beleza do agora. Assim, o poeta reconhece que o Monstro, o mundo esvaziado de sentido, é criado por nós mesmos diante do malogro de nossa condição e retifica a imagem: "O Monstro fenomenal, opíparo, / É o nosso próprio coração" (BUENO, 1998, p. 94); "Moramos no Monstro. / Habitamos nosso coração numerosíssimo" (BUENO, 1998, p. 95).

Isso significa assunção da culpa por não conseguirmos lidar com o passado histórico: "Eis nosso pecado original. Vimos demasiadamente / Enquanto todos passavam [...]" (BUENO, 1998, p. 90). O trecho atualiza a noção de "pecado original", secularizando-a. Fomos expulsos não do paraíso celeste, mas do paraíso terreno, onde a beleza era possível. A impossibilidade dessa experiência resulta na indiferença da atitude moderna. Se, depois de retificada a imagem, voltamos à primeira referência ao Monstro, substituindo-a por "coração", teríamos, ao invés de "Um corpo monstruoso que vive e que não é” (BUENO, 1998, p. 85): “um coração que vive e que não é”. Viver passivamente não é sinônimo de existência, pois tal atitude afasta ainda mais sujeito de objeto, vedando ao primeiro a possibilidade de reconstrução de sentido para a existência, contraposta a um simples estar no mundo: "Estar aqui. Estar aqui. Não virá disso, / Meus adorados irmãos, a espantosa chegada da alegria" (BUENO, 1998, p. 97). Partindo-se dessa consciência, a imagem do Monstro pode ser convertida em símbolo positivo:

A maravilha, 
Entre as maravilhas todas,

Existe, aqui,

Nos nossos olhos:

O mundo,

O turbilhonante mundo onde não tocamos, impedidos pelo Tempo,

O plácido Monstro

Feito de tudo o que existiu, que é o nosso enorme coração

(BUENO, 1998, p. 102).

O sintagma adjetivo "onde não tocamos" se relaciona primeiramente ao mundo como maravilha. Por extensão, associa-se a Monstro e a coração. Maravilha, mundo, monstro e coração se equivalem. Essa equivalência abre uma possibilidade de permanência no mundo, pois reconcilia sujeito e objeto e, consequentemente, traça um círculo em que os termos adquirem uma durabilidade para além do Tempo. Seu desejo, portanto, não é o de retomar as glórias do passado histórico, mas sim de reconstruir a forma de olhar para esse passado, ou, nos termos do poema, de tocá-lo. O Tempo, que representa "o acúmulo absoluto [...] dos eventos todos desde a inauguração das horas" (BUENO, 1998, p. 88), precisa ser convertido num instante que se perpetua:

E este agora perene pulsa, neste instante,

Como um imenso colar de contas enfiadas

Absolutamente perpendicular aos nossos olhos

Onde só a última conta se vê, e por um átimo,

Antes da próxima, embora todas existam, na extensão oculta

(BUENO, 1998, p. 84).

A imagem horizontaliza passado e presente, negando o valor de oposição entre eles. Embora o passado seja uma sucessão de presentes, o agora é eterno. Ou melhor, eternizável, desde que sustido por um lastro de "entusiasmo", o qual a força da imagem pulsante ilustra. O poema oferece, pois, uma alternativa frente à condição alienante da modernidade, por mais que seja fictícia e precária.

E então, quando esta ficção se pergunta que oferta poderia ela dar Às sombras outras que a secundam, que pequena oferenda 
De suas mãos ornaria um pouco o altar onde os mundos se sacrificam

Perante um deus que é a sua ausência, quando ela tenta

Retirar das suas entranhas de vento o singelo legado

Do amor, seu padrão de conquista antes de resvalar nas trevas,

$\mathrm{O}$ que receberia a vida de mais sem valor, de mais gratuito, de mais

[obscuro

Talvez que estas palavras? Mas se um único as acolhesse,

Um outro que a seu modo não foi, tudo se cumpriria

(BUENO, 1998, p. 92).

A ideia de que a arte oferece resistência às condições opressoras que dominam a modernidade é tributária da estética romântica ${ }^{9}$. Não da concepção do gênio, do artista agraciado por uma força divina, mas sim da ideia de que a arte, como "operação mais completa do espírito" (NUNES, 1978, p. 58), é capaz de conscientizar o indivíduo de sua subjetividade. A relação do homem com o mundo é intermediada pelo sensível, e só depois passa por um processo de racionalização, que é a tomada de consciência da realidade:

Começo incondicionado, a autoconsciência, trama formada na intuição intelectual de mim mesmo que possibilita o princípio gerador do saber - intuição indistinta do ato que, instaurando o meu ser, instaura, ao pensá-lo, o próprio mundo - também serve de fundamento à realidade. (NUNES, 1978, p. 57).

A arte romântica coloca em evidência o conhecimento sensível, que abriga uma dimensão ética - e também religiosa - do mundo: “[...] a arte é, para o romântico, uma experiência de verdade" (D'ANGELO, 1998, p. 62; grifo do autor).

\footnotetext{
${ }^{9}$ A ideia de que a arte encerra conhecimento é, na verdade, tão antiga quanto sua própria gênese. Aristóteles (1997, p. 28) assim distingue o historiador do poeta: “[...] a diferença está em que um narra acontecimentos e o outro, fatos quais podiam acontecer. Por isso, a Poesia encerra mais filosofia que a História; aquela enuncia verdades gerais; esta relata fatos particulares." Porém, há uma diferença de perspectiva que separa a concepção tradicional da concepção romântica: "[...] enquanto que na posição tradicional é a verdade que é nascente da beleza, para os românticos é antes a beleza que é fonte da verdade." (D'ANGELO, 1998, p. 65). Ou seja, se, para a primeira, realidade e verdade estão presentes em toda forma de arte autêntica, para a segunda, a proposição se inverte: é a arte que produz verdade e possibilita o acesso à realidade.
} 
Nesse sentido, a forma de expressão poética, dentro das artes literárias, tem espaço privilegiado, pois a expressão subjetiva é traço distintivo da lírica em todos os tempos. Porém, os românticos acentuam esse traço, e o fixam na figura do poeta: "O poeta é um homem que sente mais vivamente que os outros homens, possuindo uma sensibilidade mais ampla, e que tem, sobretudo, uma maior capacidade de exprimir os pensamentos e os sentimentos que se produzem nele." (D'ANGELO, 1998, p. 124). Além disso, elevam a poesia à categoria de conhecimento que mais legitimamente é capaz de apreender a realidade.

Em Entusiasmo, o poeta se apresenta como aquele que abriu "demasiadamente os olhos no lusco-fusco das ruas" (BUENO, 1998, p. 89). Essa qualidade sensível é, ao mesmo tempo, uma espécie de maldição, irrevogável desde Les fleurs du mal de Baudelaire (1857; 1972). Na primeira estrofe do poema de Bueno, já citada, o poeta é alguém que se ergue de dentro de um pântano, pois ao fruir a vida alheia perde os próprios contornos. Ou, como nesta passagem em que o poeta é seu próprio interlocutor:

Abre, vaga e branda alminha inidentificável, a profusão das portas.

Invasora de domicílios, ventanista de alcovas, persona non grata de

[alegrias,

Vai e fareja, para odiá-los, os corpos alheios que estrebucham,

Ampara, nos hospitais, as dispnéias de quem não conheces,

Chora pelas agonias anônimas, pelas faces hipócritas sós, pelos

[últimos suspiros dos macróbios,

Entra em todas as salas, espiona em todos os quartos, escancara todos

[os armários,

E os banheiros, e as gavetas de roupas íntimas, e as cédulas

[escondidas nos desvãos,

E os retratos de amantes dentro de livros, e as cartas de adultério em

[escritórios,

E os álbuns de retrato dos mortos, e as flores fanadas entre versos,

E os baús com os brinquedos esquecidos de crianças,

Entra por dentro de tudo e vê, afinal, mais pobre ainda,

O quanto tudo é alheio aos próprios senhores, aos próprios autores, às

[próprias vidas,

Tão alheio quanto a ti 
$[\ldots]$

(BUENO, 1998, p. 92-93).

A imagem do poeta oferecida nestes versos é algo risível. Sua sensibilidade é tratada com desprezo, pois não tem utilidade. O que ela consegue depreender do mundo é tão alheio quanto o próprio poeta, porque o é mesmo em relação a quem detém a posse dos objetos enumerados. Condenado a lidar com a palavra, o poeta a rejeita: “[...] Não quero / As palavras - palavra, coisa insignificante, / Detida nas alfândegas, valetudinária no tempo, diversão dileta / Dos impotentes. Quero a visão [...]” (BUENO, 1998, p. 83). A visão aqui requerida, diferentemente da configurada como pecado original, é aquela que consegue apreender o mundo de forma integral e que, consequentemente, resgata a existência do sujeito que então se reconhece no outro e no mundo exterior, como ocorrerá ao final do poema.

A subjetividade do poeta é negada em Entusiasmo através de um artifício de linguagem pautado na contradição, já que a voz que declara a primeira pessoa ao mesmo tempo nega a validade de sua própria existência: a primeira pessoa só existe na afirmação da voz que fala e, portanto, não pode conter sua própria negação, da mesma forma que essa negação não sustém sua existência. Mais do que o estranhamento causado pela linguagem que não se ratifica na pessoa de um sujeito empírico, depara-se com o estranhamento da assunção de uma ironia pungente no cerne dessa linguagem, direcionada aos procedimentos que legitimam o já desvelado artifício discursivo. "Para além da auto-referência e da auto-suficiência da arte, questionando seu próprio estatuto, a ironia é o critério", diz Compagnon (1996, p. 127) na conclusão de seu livro sobre os paradoxos da modernidade.

Conceito que ganhou visibilidade no Romantismo, a ironia é, para Kierkegaard (1991, p. 212), "uma determinação da subjetividade". O sujeito utiliza-se da linguagem para fazer que o fenômeno não coincida com a essência; para isso, ele deve ter consciência do seu projeto subjetivo de linguagem, porque, do contrário, a não coincidência entre fenômeno e essência passa a constituir um problema de clareza e não resulta no efeito de sentido pretendido. Daí a ironia ser, a princípio, uma figura de linguagem que "supera imediatamente a si mesma" (KIERKEGAARD, 1991, p. 216): torna-se significação na medida em que se desfaz. Mas a ironia não é só isso: é também um fim em si, e não tem outra intenção que não o sentir-se livre, já que “[...] o sujeito se 
liberta da vinculação à qual está preso pela continuidade das condições da vida [...]" (KIERKEGAARD, 1991, p. 222), quais sejam, a da coincidência entre essência e fenômeno. Para isso, a ironia deve se dirigir não contra uma situação ou sujeito particular, mas “[...] contra toda a realidade dada em uma certa época e sob certas condições.” (KIERKEGAARD, 1991, p.221). A liberdade conseguida com a ironia é, no entanto, algo negativa, porque o sujeito se torna “[...] flutuante, suspenso, pois não há nada que o segure.” (KIERKEGAARD, 1991, p. 227). Essa negatividade já sugere o lugar que a liberdade da subjetividade irá consolidar para a poesia, tendo na figura do poeta um indivíduo à margem dos processos de socialização.

A ironia em Entusiasmo parte das condições históricas que definem a subjetividade para chegar à sua negação. Ela não aniquila a si mesma, dado que não circunscreve, nos termos que a constituem, o que seria fenômeno e essência, a fim de que possam ser desvendados; antes, dirige-se aos dois termos simultaneamente. Ela fala contra algo que a determina, ou seja, a consciência subjetiva que, procurando libertar o sujeito, terminou por acentuar o valor negativo dessa liberdade roubando-lhe o ponto de referência para a definição do limite de sua subjetividade. Portanto, a ironia da voz poética está não só centrada em si mesma, como fala contra si mesma. É nesse sentido que em Entusiasmo a ironia se distingue da ironia romântica: não a auto-ironia, que se afigura como uma forma de conhecimento da subjetividade (GUINSBURG; ROSENFELD, 1993, p. 288), mas a ironia contra si mesma, que nega a veracidade do seu ponto de partida e, consequentemente, a possibilidade de autoconhecimento.

A negação do eu por parte do poeta resulta na negação da palavra, porque ela impede que a inexistência se concretize: “Ah, quem nos dera inexistir!” (BUENO, 1998, p.91). Mas a palavra é sua matéria-prima. Se o poeta nega sua existência, desaparece também o sujeito de linguagem que pensa o mundo através da palavra, que reorganiza através dela a realidade. O descrédito que o poeta atribui à palavra poética é, no entanto, o caminho que o levará de volta a ela, que resgatará sua existência como poeta. É preciso negar a palavra que nada retém para só então afirmar a palavra capaz de perduração. A passagem de uma a outra possibilita a passagem do sujeito alienado, indiferente ao mundo, ao sujeito tomado de entusiasmo.

A palavra capaz de perduração é aquela que fixa o instante. O passado deve ser presentificado; o presente, sustido em constância. Dado que não há o que dizer sobre a 
vida, que o heroísmo foi impossibilitado pela História e, ainda, que esta não contempla os sujeitos comuns, a maneira que o poeta encontra de eternizar o instante por meio de sua palavra é o resgate de figuras anônimas, inexistentes, que por meio de sua enunciação são trazidos à memória, o que não deixa de ser assinalado como "duvidosa imortalidade" (BUENO, 1998, p. 84).

Ah! porteiros entediados, olhando a rua através das grades,

Cópula costumeira dos párias horrendamente feios,

Vértebras doloridas dos carregadores de sacos, esclerose dos velhos

Comendo ar nas saletas escuras de subúrbio

Onde a luz não se acende para não aumentar a conta

E onde se lê numa estampa ordinária: Maior que o universo é o

[coração das Mães!

Excursões campestres ou religiosas de empregadas domésticas, toque

De cobradores na campainha, enquanto em casa todos silenciam,

Descaminhos noturnos do que eu vi na esquina [...]

Velho ourives quase falido tendo a loja assaltada às seis da tarde,

Antes tua é que é a verdade

$[\ldots]$

(BUENO, 1998, p. 87).

A apresentação das musas do poeta é correlata à matéria poética que ele identifica como possível:

Nossas musas? Os cacos das compoteiras quebradas.

Os sapatos velhos enforcados pelos cadarços nos fios elétricos.

Pernas de borboletas róseas nas valetas das ruas nossas musas.

Nossa musa o sorriso do vendedor de confeitos que não voltou um dia.

Nossa musa os gritos dentro dos ônibus amarelando o rosto da

[madrugada.

Noventa musas. Nove mil delas. Nove milhões

$[\ldots]$

(BUENO, 1998, p. 89). 
A identificação com os anônimos permite que o poeta, ao negar a própria existência, crie uma horizontalidade de condição compartilhada por todos os indivíduos, o que rompe com a ideia de hierarquia, fundamental para a concretização da alienação do sujeito moderno que não se reconhece como parte do mundo. O poema repõe a verdade no sujeito ao qual não é dado existir. A verdade aí considerada não é a dos discursos legitimadores, mas a da realidade de pessoas que, existindo como seres que experimentam a vivência cotidiana, não possuem visibilidade na História e, por isso, sofrem de um apagamento de sua subjetividade. Esse sujeito colocado à parte do processo histórico torna-se impossibilitado de realizar a existência como forma de poder, assim como o próprio poeta, cujo ofício foi destituído de utilidade. O poema assinala a condição da voz poética que, como identidade dos anônimos, reconhece a impossibilidade de se alçar a uma forma específica de existência.

A inexistência que o poeta assume identifica o sujeito com a negação de si mesmo e, consequentemente, com algo que não se constitui, para ele, em realidade apreensível. Isso funda o mistério, ao qual o poema se refere constantemente: "Algo existe. / Existe, e esse é o único mistério. / Todo o resto é nada [...]" (BUENO, 1998, p. 84). O mistério é uma instância autônoma no poema: a despeito de não o compreendermos, a ele não é negada a existência, como ocorre com o sujeito em relação à sua subjetividade, porque o mistério não contempla a si mesmo; ele existe como um fato dado, auto-suficiente, independente de um sujeito que lhe defina.

O final conclamatório a que aludimos tem lugar à luz das "boas palavras": "Dançamos. Dançamos. Ei-las, as boas palavras. / Ei-la, a embriaguez. / É preciso segurar a mão de alguém, para não perder-se o fluxo [...]” (BUENO, 1998, p. 106). E neste momento o poeta, reconduzido ao seu ofício, segue de mãos dadas com os dois anônimos que mais frequentam o poema: o mendigo flagrado defecando na calçada e o ator transformista Vanderli. Se, por um lado, o entusiasmo a que o poeta convida resguarda o sentido de alteridade do qual o termo é derivado, por outro se atualiza porque não é colocado em função de uma potência divina, já que a possibilidade de "estar em deus" foi interditada na modernidade depois do empreendimento da razão que buscou aclarar o mistério. A atualização do termo se faz sintomática da falência desse empreendimento, pois ao mesmo tempo aponta a impossibilidade da experiência com o sentido de totalidade e a necessidade de sua busca por meio da palavra poética. 
A busca pelo Uno e a fusão com o mistério empreendidas pelo Romantismo já continham a consciência da impossibilidade de sua concretização. A intensificação dessa consciência gerou a negação da busca. Em Entusiasmo, o mistério não se quer desvendado: como vimos, o poema termina com o coro dos embriagados que dança perante a porta, sem que ela se abra. A dança perante a porta indica um tipo de enfrentamento, de celebração da existência do mistério que, se não deve ser aniquilado, também não deve aniquilar o sujeito que o contempla. Entusiasmo nos propõe que olhemos nos olhos do mistério: "É preciso olhar para tudo / Com placidez absoluta" (BUENO, 1998, p. 100).

A dimensão a que o mistério se circunscreve, no contexto do poema, indica a realidade sensível que o sujeito não é capaz de apreender. Mas também aponta para o mistério manifestado como poesia, para o estranhamento proposto por uma linguagem que se configura a partir de uma lógica que lhe é própria - por isso relegada ao lugar daquilo que não se pode apreender. $\mathrm{O}$ sujeito que não reconhece sua existência se apresenta como poeta consciente da impropriedade da manifestação do estético no seu tempo. A inexistência desse sujeito, portanto, se justifica na interdição sofrida pelo fenômeno poético. Daí a ironia do poema que, ao afirmar a sua própria inutilidade, se insere no espaço que lhe é negado como instância produtora de sentido. Se a linguagem da poesia não é nem a linguagem do cotidiano nem a dos discursos legitimadores, a ironia se torna um procedimento linguístico bastante adequado a ela, porquanto se despede da comunicação centrada no discurso comum e de um olhar sobre o mundo que quer tomar posse da realidade simplificada na coincidência entre fenômeno e essência. Por trás da cortina que guarda o mistério, entrevemos a poesia.

\section{REFERÊNCIAS}

ADORNO, T. W.; HORKHEIMER, M. Dialética do esclarecimento: fragmentos filosóficos. Tradução Guido A. de Almeida. Rio de Janeiro: J. Zahar, 1985.

ARISTÓTELES. Poética. In: ARISTÓTELES; HORÁCIO; LONGINO. A

poética clássica. Tradução Jaime Bruna. Introdução Roberto de Oliveira Brandão. São Paulo: Cultrix, 1997. p. 19-52.

BAUDELAIRE, C. Les fleurs du mal. Paris: Le Livre de Poche, 1972. 
BORNHEIM, G. Filosofia do Romantismo. In: GUINSBURG, J. (Org.). O

Romantismo. São Paulo: Perspectiva, 1993. p.75-111.

BUENO, A. Entusiasmo. In: Poemas reunidos. Rio de Janeiro: Nova Fronteira, 1998. p. 83-106.

COMPAGNON, A. Os cinco paradoxos da modernidade. Tradução Cleonice P. B. Mourão et al. Belo Horizonte: UFMG, 1996.

D’ANGELO, P. A estética do Romantismo. Tradução Isabel Teresa Santos. Lisboa: Estampa, 1998.

GUINSBURG, J; ROSENFELD, A. Um encerramento. In: GUINSBURG, J. (Org.). O Romantismo. São Paulo: Perspectiva, 1993. p. 275-293.

KIERKEGAARD, S. A. Introdução à parte II. In: $O$ conceito de ironia constantemente referido a Sócrates. Tradução Álvaro Luiz Montenegro Valls. Petrópolis, RJ: Vozes, 1991. p. 211-283.

LUKÁCS, G. A teoria do romance: um ensaio histórico-filosófico sobre as formas da grande épica. Tradução José Marcos Mariani de Macedo. São Paulo: Duas Cidades/Ed. $34,2000$.

NUNES, B. A visão romântica. In: GUINSBURG, J. (Org.). O Romantismo. São Paulo: Perspectiva, 1993. p. 51-74.

PINHEIRO, P. Poesia e filosofia em Platão: a noção de entusiasmo poético. Anais de filosofia clássica, Rio de Janeiro, n. 4, p. 40-58, 2008.

TOURAINE, A. Crítica da modernidade. Tradução Elia Ferreira Edel. Petrópolis, RJ: Vozes, 1994.

VIZZIOLI, P. O sentimento e a razão nas poéticas e na poesia do Romantismo. In: GUINSBURG, J. (Org.). O Romantismo. São Paulo: Perspectiva, 1993. p. 137-156.

Artigo recebido em 10/04/2010. Aceito para publicação em 01/06/2010. 